\title{
A qualitative study of the experience of obstetric fistula survivors in Addis Ababa, Ethiopia
}

This article was published in the following Dove Press journal:

International Journal of Women's Health

8 December 2014

Number of times this article has been viewed

\section{Yenenesh Tadesse Gebresilase}

Programme Quality Department, Vita, Addis Ababa, Ethiopia
Correspondence: Yenenesh Tadesse Gebresilase

Programme Quality Department,Vita, Yeka Sub-city, PO Box 33279,

Addis Ababa, Ethiopia

Tel +25 I I I I6675269

Fax +25। II I 6675294

Email yeneneshtadesse@gmail.com
Abstract: Research on obstetric fistula has paid limited attention to the lived experiences of survivors. This qualitative study explored the evolution of survivors' perceptions of their social relationships and health since developing this obstetric complication. In-depth interviews were conducted with eight survivors who were selected based on purposive and snowball sampling techniques. Thematic categorization and content analysis was used to analyze the data. The resultant themes included participants' understanding of factors predisposing to fistula, challenges they encounter, their coping responses, and the meaning of their experiences. First, the participants had a common understanding of the factors that predisposed them to obstetric fistula. They mentioned poor knowledge about pregnancy, early marriage, cultural practices, and a delay in or lack of access to emergency obstetric care. Second, the participants suffered from powerlessness experienced during their childhood and married lives. They also faced prolonged obstructed labor, physical injury, emotional breakdown, depression, erosion of social capital, and loss of healthy years. Third, to control their negative emotions, participants reported isolating themselves, having suicidal thoughts, positive interpretation about the future, and avoidance. To obtain relief from their disease, the women used their family support, sold their properties, and oriented to reality. Fourth, the participants were struggling to keep going, to accept their changed reality, and to change their perspectives on life. In conclusion, obstetric fistula has significant physical, psychosocial, and emotional consequences. The study participants were not passive victims but rather active survivors of these challenges. Adequate support was not provided by their formal or informal support systems. To prevent and manage obstetric fistula successfully, there should be family-based interventions that improve access to and provision of emergency obstetric care. These initiatives should also ensure men's participation, women's empowerment, and the utilization of community-based institutions.

Keywords: Ethiopia, content analysis, coping mechanisms, survivors

\section{Introduction}

Motherhood should be a time of expectation and joy. However, for women in developing countries, the reality of motherhood is often grim. These women die during the normal and life-enhancing process of procreation. For every woman who dies, many more suffer from serious complications. ${ }^{1}$

Ethiopia's levels of maternal mortality and morbidity are among the highest in the world. Current estimates indicate that over 25,000 Ethiopian women and girls die each year due to complications arising during pregnancy and child birth. At the same time, more than 500,000 women and girls who survive delivery-related complications suffer from long-term disability. ${ }^{2,3}$ Among the morbid conditions that can affect women following labor, obstetric fistula is considered the most debilitating and devastating. ${ }^{4}$ 
Obstetric fistula is a medical condition that involves an abnormal opening between the bladder and the vagina (vesicovaginal fistula), between the rectum and vagina (rectovaginal fistula) or both, leading to uncontrolled leakage of urine and/or feces. It results mostly from an unattended prolonged labor. ${ }^{5}$

In Ethiopia, obstetric fistula is still a common health and social problem. ${ }^{6,7}$ The social consequences include divorce by husbands, and abandonment and ostracism by affected women's families and community. This is due to the uncontrollable leakage of urine and/or feces and the accompanying smell. Fistula also leaves women with few opportunities to earn a living, so worsens their poverty. ${ }^{8}$ Moreover, in nearly every case of fistula, a baby is stillborn, which may also lead to future inability to conceive. The death of the baby, inability to carry a child, and the stigma that accompanies fistula results in significant emotional damage. ${ }^{9}$ Cumulatively, this keeps victims from complaining about obstetric fistula. As a result, it has been difficult to determine the exact prevalence of the condition.

Based on accessible statistics in the area, the World Health Organization estimates that more than two million girls and women worldwide live with obstetric fistula, with an additional 50,000-100,000 new cases occurring every year, the vast majority of whom are in Africa and Asia. ${ }^{10}$ Of these, between 26,000 and 40,000 women with obstetric fistula live in Ethiopia. ${ }^{11}$

Research on obstetric fistula has been conducted for more than 40 years. However, this research has focused mainly on the availability, accessibility, and utilization of services. Limited attention is paid to the sociocultural factors associated with obstetric fistula ${ }^{12}$ or survivors' perception of their lives following successful repair and reintegration back into their communities. ${ }^{13}$ Generally, discussing the gaps in research on obstetric fistula, the findings of facility and community needs assessment done in 25 countries of Africa and Asia concluded that:

Obstetric fistula has remained relatively overlooked. This neglect is evidenced by scarcity of information on the extent of the problem, its underlying causes, treatment capacity, and patients' experience. ${ }^{14}$

Above all, although obstetric fistula is a serious social and health problem in Ethiopia, the existing literature focuses mainly on the magnitude of the problem, its etiology, and consequences. Such studies are helpful to show the burden of the problem, but do not contribute much to an in-depth understanding of fistula from a survivor's point of view.
Therefore, the aim of this study was to explore the evolution of survivors' perceptions of their social relationships and health since the trauma of obstetric fistula. Specifically, this research focused on women's understanding of factors predisposing to obstetric fistula, the challenges they have encountered, their coping responses, and the meaning of their experience with obstetric fistula.

\section{Materials and methods Theoretical framework}

Two theories of health behavior that help to explain obstetric fistula from different perspectives by identifying and using concepts that increase the creativity and freshness of the study are discussed, ie, the ecological model and the transactional model of stress and coping. During analysis of data, these two theories help in "informing without determining, lending concepts and ideas without imposing them". ${ }^{15}$

\section{Ecological model}

The ecological model helps to explain human health behavior by focusing on the nature of people's transactions with their physical and sociocultural surroundings. ${ }^{16}$ There are four explicit assumptions in the ecological model. First, health is influenced by multiple components of the physical and social environment, including personal attributes. Second, the environment itself is multidimensional. Third, interactions between humans and their environment can be described at varying levels of aggregation (individuals, families, work and cultural organizations, communities). Fourth, there is feedback across different levels of the environment and groups of people. ${ }^{17}$

The model shows that human health behavior is influenced by the interaction between personal, situational, sociocultural, and environmental factors, including the built environment. Inclusion of all these types of analysis provides an opportunity to see the influence of intrapersonal (level of individual knowledge, attitudes, and beliefs about obstetric care) and interpersonal (level of support from spouses, families, neighbors, and traditional birth attendants) behavioral factors on women's health and social circumstances. It also helps to explain the influence of sociocultural and environmental factors on the occurrence and consequences of fistula.

\section{Transactional model of stress and coping}

The transactional model of stress and coping explains how people cope with stressful events. When people are confronted with stress, they evaluate the significance of a stressor as stressful, positive, controllable, challenging, or 
irrelevant. This prompts efforts to cope with the stressor. However, according to this model, an increased perception of risk can also generate distress. ${ }^{18}$ When people face stress they evaluate not only the features of the stressful situation but also what they can do about it. They assess their perceived ability to change the situation and manage their emotional reaction to the threat. This will be mediated by actual coping strategies. ${ }^{18}$

This model conceptualizes coping efforts along two dimensions, ie, problem-focused and emotion-focused coping strategies. Problem management strategies, which will be more adaptive for stressors that are changeable, are directed at changing the stressful situation. These include active coping, planning problem solving, information seeking, and use of social support. Emotion-focused coping efforts, which are more suitable when the stressor is unchangeable, are directed at changing the way one thinks or feels about a stressful situation. These include seeking of social support, venting of feelings, avoidance, and denial. ${ }^{13}$

\section{Study area, study participants, and sampling}

The field work for this study was carried out at the Women for Women Foundation in Kolfe Keranio subcity, Addis Ababa, Ethiopia. The Women for Women Foundation is the only organization in Ethiopia addressing the needs of fistula victims before and after repair. ${ }^{19}$ The empirical work involved eight women who have had obstetric fistula, were clients of the Women for Women Foundation, and were living in Addis Ababa, Kolfe Keranio subcity at the time of data collection. The inclusion criteria were: female gender; age 18-24 years; a history of treatment for obstetric fistula; urban-dwelling for a minimum of 1 year; a history of untreated fistula for at least 2 years; and willingness to participate in the study.

The study used a combination of purposive and snowball sampling methods. Purposive sampling was used for tracing of the initial participant, followed by snowball sampling, ie, seeking referrals from the initial participant to identify additional participants, until data saturation was reached. This qualitative research is limited by its subjective nature and small sample size. As a consequence, the findings of this study cannot be generalized to all women who have had obstetric fistula.

\section{Data collection}

Two in-depth interviews were conducted per participant and guided by two major groups of open-ended questions. In the first interview, which took 30-45 minutes, participants were asked questions related to situations and settings that could lead to obstetric fistula. This interview also promoted the next interview through creating easiness and developing trust. In the second interview, which took 40-80 minutes, participants described experiences related to difficulties they had encountered, strategies that had helped them to cope with their problems, and the meaning they provide for their experiences of obstetric fistula. The second interview was conducted 4-6 days after the first interview.

In order to minimize respondent bias and the risk of reactivity whereby participants could withhold information due to the presence of a researcher, two interviews were conducted per participant. 15 "Bracketing out" can be used for holding back researchers' preconceived ideas about the issue under study, and this was done by forwarding open-ended questions arranged to follow the cues from participants. This enabled a full description of how participants view and feel the trauma of obstetric fistula.

This research was approved by the Graduate School of Social Work, Addis Ababa University. Permission to conduct interviews was obtained from the Women for Women Foundation. Written and verbal informed consent was obtained from each participant.

\section{Data analysis}

Data analysis started on the day of the in-depth interview. As a first step in the analysis, the audiotapes were transcribed using the rules of transcription. The second step was coding or identifying informants' words or phrases and even sentences related and relevant to the area of study. The third step was categorization, in which the identified codes were sorted into relevant categories. Finally, the main themes were identified and the categories brought together and rearranged under those themes. Significant statements were clustered into themes, forming the "architecture of the findings", ${ }^{15}$ and are used to describe what the participants experienced and the context that influenced how the participants experienced the phenomenon. This focuses on the common experiences, as well as different experiences among the participants. ${ }^{15,20}$

\section{Results Understanding of factors predisposing to obstetric fistula}

Eight women who had suffered from obstetric fistula participated in this study. They were aged 20-24 years and had lived with obstetric fistula for 2-4 years. All had been married (one was separated and seven were divorced). None had children. Six were able to read and 
write because of a year-long literacy program they had joined after treatment for their fistula, and two were educated through to grade 5. All of the respondents came from a remote part of Ethiopia (Table 1) and had accessed surgical treatment, enabling them to maintain continence.

When the participants were asked to share their understanding of possible predisposing factors for obstetric fistula, most noted that a change in their knowledge about the condition occurred after visiting health facilities (particularly Addis Ababa Fistula Hospital). Before this visit, the main risk factors mentioned by seven of the eight participants were "being cursed", "the will of God", "evil spirits", "it is because of God", "family has done something bad to God", "I don't know", and "it is my fate". However, one participant mentioned both early marriage and the lack of a capable health professional on hand to ensure the safety of women during child birth, saying "I arrived at the nearby health center in good condition. Lately, she sent me to the hospital. The doctor, however, couldn't protect me from the fistula."

As time passed, change was evident in participants' understanding of factors predisposing them to obstetric fistula. The majority of the participants stressed "lack of decision power" and "non-availability of transportation services, well equipped health centers, and skillful health professionals". Two of the participants, however, described early marriage compounded by lack of antenatal and emergency obstetric care, which was aggravated further by cultural practices and a lack of well-equipped health centers and knowledgeable health professionals. One informant explained these factors by stating her own experience:

My family was encouraging me to give birth at home.

During labor, I was taking herbs and they were massaging me .... When they took me to the health center, the health worker spent a day monitoring my status .... Finally, he told us that it was beyond his capacity. So, they brought me back

to home. I delivered at home.

It was essential for participants to seek an answer to the question of why they had experienced obstetric fistula. However, two participants experienced confusion when explanations did not correspond to their inner feelings and realities. As a result, they were more inclined to see "the will of God" and "fate" as reasons for obstetric fistula. One participant stated that "When I see my friends who married at an early age and gave birth at home without any problem, I started questioning the reasons I learned so far. For me, it is also the will of God and your fate."

\section{What are the challenges encountered by fistula survivors?}

\section{Powerlessness}

The participants described the powerlessness experienced during childhood and their married lives. The powerlessness during childhood was mostly related to "too many domestic responsibilities and farm duties", "the existing tradition", "lack of freedom", and "marriage consummation before or immediately following menarche". While describing their childhoods, all of the participants felt angry, blaming their families and the tradition that discourages education for girls, and identified these as the main reasons for their current situation. One participant stated: "In our area, the ultimate goal of families is to prepare girls for marriage not for school." At the same times, six of them mentioned being happy that they could read, write, and sign their names within one year of joining the literacy program.

Participants also experienced powerlessness in their married lives. All were married too early (at the age of 9-13 years), did not know their husbands beforehand, did not know they were about to be married, and did not want to get married (particularly for their first marriages). Three had married more than once. Six also mentioned that they were not happy

Table I Background of participants

\begin{tabular}{|c|c|c|c|c|c|c|}
\hline Informant & Age, years & $\begin{array}{l}\text { Educational } \\
\text { level }\end{array}$ & Marital status & $\begin{array}{l}\text { Age at OF } \\
\text { occurrence }\end{array}$ & $\begin{array}{l}\text { Delay before } \\
\text { treatment, years }\end{array}$ & $\begin{array}{l}\text { Number of } \\
\text { surgeries }\end{array}$ \\
\hline I & 20 & Fifth grade & Separated & 14 & 2 & 3 \\
\hline 2 & 23 & Literate & Divorced & 16 & 2 & I \\
\hline 3 & 21 & Literate & Divorced & 12 & 3 & I \\
\hline 4 & 24 & Literate & Divorced & 17 & 4 & I \\
\hline 5 & 23 & Literate & Divorced & 15 & 3 & 2 \\
\hline 6 & 20 & Literate & Divorced & 11 & 2 & I \\
\hline 7 & 22 & Fifth grade & Divorced & 14 & 4 & I \\
\hline 8 & 21 & Literate & Divorced & 15 & 2 & I \\
\hline
\end{tabular}

Abbreviation: OF, obstetric fistula. 
with their married lives, and attributed this to "departing from the family", "dropping out of school", "oppressing tradition", "lack of decision-making power", and "too many domestic responsibilities". However, two of the participants indicated that they were happy with married life when compared with the lives they were living with their parents, and had found a person who shared the household responsibilities and gave them respect and love.

\section{Prolonged and obstructed labor as a traumatic event}

None of the participants had sought antenatal care during their pregnancies, mainly due to poor awareness of and access to antenatal services. Two also mentioned a feeling of shame about receiving care as another reason. All eight women reported prolonged labor of at least 4 days, with indescribable suffering. Five finally gave birth at a health facility with skilled attendants, but all started their labor at home and suffered for days or weeks. During this time, they were assisted by their mothers, neighbors, or relatives. Many were taken to health facilities after losing sensation from the waist down (due to obstructed labor). This was due to delayed decision making to seek a health service and a delay in reaching the health center. One participant noted that

I spent nine days in labor. My family tried all traditional practices. However, I was getting tired and I couldn't bear the pain anymore. Finally, after I lost sense from the waist down, they took me to the health post and I gave birth there.

All of the participants reported that they had been subjected to traditional practices used by the community to minimize the pain associated with labor. These practices included massaging, being turned upside down, traditional medicines made from a number of herbs, visiting traditional healers, and arranging continuous coffee ceremonies.

\section{Emotional challenges associated with obstetric fistula \\ Body as a barrier}

All participants experienced physical changes, such as weight loss, loss of bodily control, pain around the pelvis, physical exhaustion, and an inability to walk or work. Descriptions were physical, but all had an accompanying feeling of dependency. The extensive experience of the body as a barrier and losing independence was particularly evident in the following description given by one participant:

Full of pain, can't eat as usual, becoming too thin, spending most of the time lying on a bed and crawling in the house like a child and being dependent on people for simple things, like eating, drinking, and dressing.

All of the participants also indicated that the emotions related to their physical challenges affected their relationships at home, with friends, and with their husbands. These feelings resulted in a loss of control over daily routines, ie, self-care, household chores, and filling the role expected of a wife in the community. One participant reported being "envious" of her friends when she saw them "being healthy and raising their children".

\section{Anger, sadness, and shame}

Participants experienced the anger, sadness, and shame associated with loss of a child, as well as the loss of ability to work and acceptance and support by their husbands, family members, relatives, classmates, community members, and other passengers when using public transport. Participants also reported experiencing bad moods, feeling morally weak, waiting for the end, and asking "Why only me?" Participants' responses regarding the anger and sadness they experienced shows that they continuously felt emotional disturbance.

I lost not only my health, but also my child. It was a double punishment. I also faced rejection from my father. After I was cured, when I went back home, my father was the first person to cry. But, the emotional pain is still inside me.

All participants except two who traveled in car facilities arranged by non-governmental organizations reported their feelings of sadness and shame when mistreated by fellow passengers on public transport. This was due to the smell of urine that began immediately after starting the journey to Addis Ababa Fistula Hospital. They used different strategies to cope, like paying a double fare, explaining their situation, and sitting near a window. Nonetheless, they were only able to travel a short distance peacefully, as passengers could not tolerate the smell. Only three of these six participants reported using public transport. The remaining three traveled in the back of trucks after they were forced to leave their bus. These women suffered more since sitting in an uncomfortable place was not easy.

\section{Fears about the future}

Participants felt that the future was frightening and uncertain in relation to having partners, marriage, sex, becoming pregnant, giving birth, and reintegrating back to their local communities. They were afraid of experiencing obstetric 
fistula and its associated challenges again in the future. In relation to this, one participant stated:

There is one thing that I don't look forward to ever ... starting a family and having children. To me, it means living a terrible life again.

Another respondent noted:

People ask me the reason for not giving birth. It was three times I underwent operation. To me, giving birth to a child means losing my life. I also remember how painful the first sex was after fistula repair. Even now, I don't want to have sex frequently since it has pain.

\section{Coping mechanisms}

Participants used two general strategies, ie, problem-focused and emotion-focused, for coping with everyday routines that were disrupted by their illness. Most participants predominantly used one type of strategy over the other.

\section{Problem-focused coping}

Participants utilized various constructive strategies and resources to reorganize their daily lives based on the nature of the event they experienced and the resources they had. This involved seeking family support, selling their property, and orientating to reality.

All respondents used the family as the primary survival mechanism, particularly before they had access to fistula repair. They generally received social and emotional support and were accepted by at least one family member. In some instances, they received financial support as well. The reasons that motivated them to seek support from the family were: "I could not be a wife", "it is the duty of the family", "I had no place to go", and "I had no choice". Although the family was often the only source of support, particularly after divorce, most participants experienced problems when living with their families.

When my husband divorced me, I went to my mother's

house. When my mother passed away, I went to my uncle's

house because I had no choice.

Although the initial fear and shock were overwhelming, their attendance at Addis Ababa Fistula Hospital in itself became a means for social recovery. As time passed, all participants used orientating to reality as a problem-focused coping strategy, seeking to find out more about the cure rate, treatments, and difficulties that could occur during treatment from other women who had been treated for obstetric fistula. Participants described how discussions among themselves provided strength and a feeling of pleasure in being together.

All of the participants had the opportunity for skills training in embroidery, hairdressing, basketry, and bead-making in order to generate their own income. However, they preferred hairdressing and bead-making. This is because hairdressing and bead-making require minimal energy and therefore fit better with their health situation. Hairdressing also gave them the opportunity to generate a better income and to interact with a range of people.

\section{Emotion-focused coping}

When participants experienced stressful events that were relatively tolerable, but not necessarily amenable to direct action, they used at least one emotion-focused coping strategy, ie, isolating themselves or suffering in isolation, suicidal thoughts and attempts, positive subjective interpretation, and avoidance.

Suffering in isolation was one of the emotion-focused coping strategies developed by the respondents. Five women reported that their friends, neighbors, or relatives had invited them to social events, but none wanted to accept these invitations. They preferred to withdraw from social activity and spent most of their time alone. This was because they were afraid of leaking urine and its smell, depression, and feeling anger and shame when they saw their friends.

The stigmatizing nature of obstetric fistula, compounded by traumatic experiences like insults from the community and family members, made their lives more challenging. In addition, they had "a feeling of being inferior, sinful, and shamefully different, and losing hopes on the future". As a result, six participants had had suicidal thoughts, and one had attempted suicide as a way out. The following response illustrates this subtheme:

You have to live with it and deal with all challenges. But, sometimes I planned to take some kind of medicine and become dead; just to get relief.

Participants also used subjective positive interpretation to restore their self-confidence and their ability to cope. This involved simply believing in their ability to cope through learning from the experience of others, saying: "Other patients coped and became healthy. I can also be like them, can't I?" Moreover, participants gained confidence by "trusting in the care provided by health care providers".

One respondent stated that "Some of the ex-patients were nurses while others were doing laundry and other activities. 
Then, I started to say, "why not me?"' Participants also accepted the changes they experienced by saying "It is the will of God", "It is my fate", and "I am not the only one" as another coping strategy for subjective positive interpretation. This enabled them to adapt to the changes they experienced because of obstetric fistula.

With regard to future reintegration into their own communities, none of the participants wanted to go back to their villages, preferring to avoid the stigma and discrimination resulting from being a woman with a fistula. Participants also mentioned that the countryside's reality, including health facilities, and agricultural activities they are expected to perform, could not fit with their health condition. This sentiment was demonstrated in the following statements:

"There you can't be alone", "they don't believe that you are healthy and self-sufficient", "there is a heavy workload", "their words hurt you", "I don't have anybody there", "no means of income", "living alone is equivalent to being a prostitute", "country side life is not suitable for follow-up", and "Addis Ababa is women's place".

\section{Struggling to keep going}

Participants' responses concerning the meaning of their experience of obstetric fistula indicated that they were struggling to keep going. This issue contained four subthemes: feeling joy in being healthy, viewing obstetric fistula as an opportunity to live a better life, motivation to change their life perspective, and a reason for loss of identity.

\section{Feeling joy in being healthy}

Participants felt joy in having made positive changes in their lives after fistula repair, including emotional, social, and economic changes. This was true, even if their current lives had some challenges and involved great responsibility. They described their feelings about their lives after medical treatment as follows: "it was like being born again", "it was a miracle", "it was the work of Jesus", and "it was becoming a person again". Participants gave this subtheme meaning by describing the changes that occurred after treatment in terms of doing what they wanted to do, interacting with people without shame and fear, and regaining their healthy status.

\section{An opportunity to live a better life}

Four of the women described obstetric fistula as an opportunity to live a better life, ie, one with more freedom and power. They found deep satisfaction in the knowledge that they were living alone in their homes and taking care of their homes and themselves. Because they lived alone, they perceived a real freedom and power to do as they pleased and planned. They also spoke with some satisfaction about keeping their minds alert by participating in a number of activities. One participant reported "I am doing everything by myself. There is nobody whom I ask for permission, only me to answer to."

\section{Motivation to change life perspective}

Participants also described obstetric fistula as a motivation to change their perspective on life. Some indicated that they became a person "who understands and cares about people in trouble", "who has future plans", and "who is spiritually strong". In relation to this, one informant stated that

If I didn't have a fistula, I would probably still be a person without sympathy. Now, I have become a person who easily understands people's needs and problems.

Some also described themselves as being "a strong independent woman" and a "more inner-oriented woman". One participant explained her change in life perspective as follows:

I never thought of myself before. It was always my family, my husband or some of my friends. Now life gave me big lesson and I don't want to think about anybody else. I feel that I have become self-centered, but it is necessary to survive and become happy.

\section{Loss of personal identity}

Two participants described obstetric fistula as the reason for their loss of personal identity. In a society in which the role of a wife is primarily to bear children and take care of household chores, it is mandatory for women to do this if they are to retain their family and social position. That is often possible for those who live with family and relatives. One of these two participants reported feeling lonely because she lived alone, while her sisters and brothers lived in Gonder. "Here, nobody knows me. If I were in my village my family is well known and people call me by associating with my family." Another informant stated that "because of my illness, I went from being a healthy wife and woman with relatives to an ill, divorced, and lonely person".

\section{Discussion}

The study participants' understanding of predisposing factors is interpreted in light of an ecological model of health 
behavior, distinguished by its multilevel nature. ${ }^{17}$ Individual factors include: perceiving obstetric fistula as a curse, an evil spirit, or a punishment from God; poor knowledge about pregnancy and the associated risks; being illiterate; being powerless at the household level; and not utilizing antenatal care. Family factors include encouraging early marriage and cultural practices. Societal factors include social acceptance of early marriage, cultural practices, and home delivery, as well as societal views towards antenatal and emergency obstetric care. Environmental factors include a delay in or lack of diagnosis, treatment, or follow-up, failure to refer, long distance from a health center, and a lack of well-equipped health centers, skilled health personnel, and transport.

Almost all of the participants held common initial and current understandings of the factors contributing to obstetric fistula. The women also mentioned the relationships between obstetric fistula and cognitive, gender, family, social, and environmental factors. These findings are consistent with those of other studies..$^{7,21,22}$ In addition, as the ecological model hypothesis shows, ${ }^{16}$ participants' understanding varies with time and place as a result of ecological changes, including being exposed to former patients, medical staff, treatment, and post treatment rehabilitation.

Exploring the challenges faced by fistula survivors, the powerlessness these women experienced during their childhoods and married lives contributed to a lack of education, freedom, leisure time, and power to make their own choices and decisions related to marriage, health, sexuality, and reproduction. This is consistent with previous research reporting the low status of women as an important factor contributing to the risk of obstetric fistula. ${ }^{12,21-23}$ Participants' poor knowledge about the risks associated with pregnancy and their poor access to health and transport services further adversely influenced their health status. This supports the view that not only the occurrence but also the severity of obstetric fistula is explained by a woman's way of life in a given geographic and social setting. ${ }^{24}$ As reported elsewhere, ${ }^{13,25-27}$ participants in this study experienced emotional challenges, including feelings of anger, sadness, and shame due to the loss of a child and the ability to work, divorce, stigma, and discrimination on the part of family, community members, and fellow travelers.

Fistula repair, rehabilitation, and counseling services each made their own contributions towards improving health status, self-esteem, and social life in these women. However, as some studies indicate, such women may be fearful about the future and lack interest in sex, marriage, establishing a family, and childbearing. ${ }^{23,28}$ Fear about the future extends to the challenges they will experience and re-experience in trying to reintegrate into their local community. These challenges include poor access to health facilities, a lack of social acceptance, and a lack of jobs suited to their health situation. In this regard, as in other studies, although treatment proved very helpful, it was still difficult for these women to fully enjoy family and community life. ${ }^{5,29}$ This clearly indicates that the same conditions in society that predisposed them to obstetric fistula also denied them the social and emotional support necessary to deal with their trauma, although some family and community members did meet this need..$^{23,29}$

The challenges encountered by the participants, as some previous research has already shown, ${ }^{30}$ indicate that obstetric fistula takes a high personal toll in terms of pain, divorce, suffering, losing a baby, emotional breakdown, depression, physical injury, and being deprived of basic human rights. This obstetric complication also has a number of socioeconomic and health costs, including rejection, expenditure on psychosocial and medical support, erosion of social capital, and loss of healthy years.

According to the transaction model of stress and coping, when people face challenges, they focus their efforts on emotions and problem solving. ${ }^{18}$ Participants in this study made similar efforts to regulate their emotions through suicidal thoughts, avoiding family and community members, suffering in isolation, hiding their story and circumstances, accepting the changes associated with obstetric fistula, and positive subjective interpretation. The most helpful knowledge that participants could obtain came from others in the same situation. This provided comfort and helped them to keep going and be able to understand and accept obstetric fistula. Participants also attempted to manage the disease by seeking family support, selling property, and orientating to reality.

To avoid the social rejection, stigma, and discrimination arising from being a woman with a fistula, the participants did not reintegrate into their family and local community. In a similar vein, Plummer described how social responses, including stigmas and labeling, have their own effects on social behavior and personal identity. This is because the person takes on the label. ${ }^{31}$

The participants adopted coping mechanisms based on the specific event they had experienced and the resources they had. This enabled them to overcome challenges and accept the change they experienced. The literature emphasizes the physical, economic, and psychosocial challenges experienced by women with obstetric fistula. ${ }^{25,29,32}$ The findings of 
the present study show that such women can survive these challenges, and that they have strengths and coping skills that could be built upon to make their lives better.

Participants struggled to keep going. They had regained their joy of living and experienced feelings of satisfaction, delight, and meaning. This is because the life they once had existed again and they had the opportunity to live with freedom and more decision-making ability. They were also able to take responsibility and care for themselves again. Similar findings have been reported by Morse and Carter, who found that once people have suffered enough and are able to accept their changed reality, they gain new insight and appreciation of life and their changed reality. ${ }^{33}$

Struggling to keep going is also related to integrating the changes caused by obstetric fistula by developing new perspectives on life. In this way, participants developed a vision of hard work, the desire to change their status, and sympathetic feelings toward others. They also became less dependent and more self-centered. Similarly, Morse et al stated that, to feel integrated with the world again and to be able to be included, one must go through the process of learning to live within new limits and define life in ways that accommodate these changes. ${ }^{34}$

\section{Conclusion and implications}

Obstetric fistula is a complex problem and is related to personal, situational, and sociocultural conditions. This makes it difficult to identify causes of obstetric fistula that fit every individual. The participants in this study had a common understanding about the factors that exposed them to fistula, although this varied with time and location due to changes in the person's environment.

Obstetric fistula has far-reaching physical, psychosocial, and emotional consequences. Women suffering from the condition develop diverse mechanisms to cope with the disease and deal with their emotions. Hence, they realize that they are not passive victims but rather active survivors of these challenges. However, women's responses are often limited by the existing coping options and vary with time and the challenges they face. This indicates that they lack adequate support and appropriate attention from their formal and informal support systems.

This study provides a deeper understanding of what it means to be a survivor of obstetric fistula. It also reveals how fistula victims exist and strive to gain meaning from the experience of being diagnosed with a condition, recovery from illness, and living a "normal" life. It is reasonable to conclude that this process of understanding the context of obstetric fistula, survivors' feelings, predisposing factors, coping mechanisms, and interpretation of their situation is an important basis for development of appropriate corrective interventions.

Essential obstetric services should be expanded at the community level to address obstetric fistula through prevention and management. Comprehensive information on birth preparedness and taking action on delays should also be provided. Further, small, low-cost emergency obstetric units must be established within the existing health system in remote and underserved areas of the country.

Effective treatment for fistula that includes reconstructive surgery, psychosocial therapy, and income-generating skill building addresses one side of the problem. This implies that obstetric service initiatives should bring together different concerned bodies at different levels. These initiatives should also be family-based and ensure men's participation and women's empowerment. Such initiatives further need to treat the woman as a whole person, ie, as an individual, a family member, and a community member, with equal attention paid to her physical, socioeconomic, psychosocial, and spiritual well-being.

The government of Ethiopia has implemented policies and signed major declarations and conventions to protect maternal health and promote safe motherhood. However, the findings of this study indicate that these policies and declarations are not yet fully implemented, and suggest that concerned bodies should critically analyze the following questions. Are they dealing with maternal health up to the demands of women residing in the rural part of the country? How wide is the gap between claims and realities regarding women's maternal health? How should this gap be addressed when taking sociocultural factors into consideration?

\section{Acknowledgments}

The author would like to acknowledge Dr Haile Michale Tesfahune and Dr Tekle-Ab Mekbib for their invaluable comments and provision of relevant materials. Special thanks to Rebekah Kiserm, Director of the Women for Women Foundation, for her willingness and positive response that facilitated this study. The author thanks the women who gave of their precious time to share their personal experience. Finally, the author acknowledges Dr Abeba Tadesse for editing this work. The author had full access to all the data in the study and takes responsibility for the integrity of that data and the accuracy of its analysis. 


\section{Disclosure}

The author reports no conflicts of interest in this work.

\section{References}

1. World Health Organization, United Nations Children's Fund, World Bank. Reduction of maternal mortality. 1999. Available from: http:// whqlibdoc.who.int/publications/1999/9241561955_eng.pdf. Accessed August 31, 2014.

2. Central Statistical Agency (Ethiopia) and ORC Macro. Ethiopia demographic and health survey. Addis Ababa, Ethiopia: Central Statistical Agency (Ethiopia) and ORC Macro; 2005. Available from: http:// dhsprogram.com/pubs/pdf/FR179/FR179[23June2011].pdf. Accessed August 31, 2014.

3. Hill K, AbouZhar C, Wardlaw T. Estimates of maternal mortality for 1995. Bull World Health Organ. 1995;79:182-193.

4. Angioli R, Gómez-Marín O, Cantuaria G, O’Ssullivan MJ. Severe perineal lacerations during vaginal delivery: the University of Miami experience. Am J Obstet Gynecol. 2000;182:1083-1085.

5. Mselle LT, Kohi TW, Mvungi A, Evjen-Olsen B, Moland KM. Waiting for attention and care: birthing accounts of women in rural Tanzania who developed obstetric fistula as an outcome of labour. BMC Pregnancy Childbirth. 2011;11:75.

6. Wall LL. Dead mothers and injured wives: the social context of maternal morbidity and mortality among the Hausa of Northern Nigeria. Stud Fam Plann. 1998;29:341-359.

7. Kelly J, Kwast BE. Epidemiologic study of vesicovaginal fistulas in Ethiopia. Int Urogynecol J. 1993;4:278-281.

8. Donnay F, Weil L. Obstetric fistula: the international response. Lancet. 2004;363:71-72.

9. Hamlin EC. Preventing fistula: transports role in communities for health in Ethiopia. (August 30 to September 13, 2004). Available from: http://webcache.googleusercontent.com/search?q=cache:B XFtYYRXfvEJ:siteresources.worldbank.org/INTPH/Resources/ BTOTransportsrolinempoweringcommunitiesfoealthinEthiopia. $\mathrm{doc}+\& \mathrm{~cd}=1 \& \mathrm{hl}=\mathrm{en} \& \mathrm{ct}=\mathrm{clnk} \& \mathrm{gl}=\mathrm{nz}$. Accessed August 31, 2014.

10. World Health Organization. The Prevention and Treatment of Obstetric Fistula: Report of a Technical Working Group. Geneva, Switzerland: Division of Family Health; 1989.

11. Central Statistical Agency (Ethiopia) and ORC Macro. Demographic and Health Surveys of Ethiopia. Addis Ababa, Ethiopia: Central Statistical Agency (Ethiopia) and ORC Macro; 2005. Available from: http://www. dhsprogram.com/pubs/pdf/FR179/FR179\%5B23June2011\%5D.pdf. Accessed August 31, 2014.

12. Roush KM, Kurth A, Hutchinson MK, Van Devanter N. Obstetric fistula: what about gender power? Health Care Women Int. 2012;33: 787-798.

13. Mselle LT, Evjen-Olsen B, Moland KM, Mvungi A, Kohi TW. "Hoping for a normal life again": reintegration after fistula repair in rural Tanzania. J Obstet Gynaecol Can. 2012;34:927-938.

14. Velez A, Ramsey K, Tell K. The campaign to end fistula: what have we learned? Findings of facility and community need assessments. Int J Gynaecol Obstet. 2007;99 Suppl 1:S143-S150.

15. Padgett KD. Qualitative Methods in Social Work Research. 2nd ed. Thousand Oaks, CA, USA: Sage Publications; 2008.

16. Glanz K, Rimer B, Lewis FM. Theory, research, and practice in health behavior and health education. In: Glanz K, Rimer BK, Lewis FM, editors. Health Behavior and Health Education: Theory, Research and Practice. San Francisco, CA, USA: Jossey-Bass; 2000.
17. Sallis FJ, Owen N. Ecological models of health behavior. In: Glanz K, Rimer BK, Lewis FM, editors. Health Behavior and Health Education: Theory, Research and Practice. San Francisco, CA, USA: Jossey-Bass; 2000 .

18. Wenzel L, Glanz K, Lerman C. Theory, research, and practice in health behavior and health education. In: Glanz K, Rimer BK, Lewis FM, editors. Health Behavior and Health Education: Theory, Research and Practice. San Francisco, CA, USA: Jossey-Bass; 2000.

19. Debra H, Rebekah K. History of the Trampled Rose project. Available from: http://www.trampledrose.org. Accessed May 13, 2011.

20. Creswell WJ. Qualitative Inquiry and Research Design. Choosing among Five Approaches. 2nd ed. Thousand Oaks, CA, USA: Sage Publications; 2007.

21. Muleta M. Socio-demographic profile and obstetric experience of fistula patients managed at the Addis Ababa Fistula Hospital. Ethiop Med J. 2004;42:9-16.

22. Muleta M, Hamlin EC, Fantahun M, Kennedy RC, Tafesse B. Health and social problems encountered by treated and untreated obstetric fistula patients in rural Ethiopia. J Obstet Gynaecol Can. 2008;30:44-50.

23. Kabir M, Iliyasu Z, Ababubacker IS, Umare UI. Medico-social problems of patients with vesico-vaginal fistula in Murtala Mohammed Specialist Hospital, Kano. Ann Afr Med. 2003;2:54-57.

24. Walley LR, Kelly J, Matthews MK, Pilkington B. Obstetric fistula: a practical review. Rev Gynecol Pract. 2004;4:73-81.

25. Ahmed S, Holtz AS. Social and economic consequences of obstetric fistula: life changed forever? Int J Gynaecol Obstet. 2007;99:10-15.

26. Mwini-Nyaledzigbor PP, Agana AA, Pilkington FB. Lived experiences of Ghanaian women with obstetric fistula. Health Care Women Int. 2013;34:440-460.

27. Zheng AX, Andreson JW. Obstetric fistula in low-income countries. Int J Gynaecol Obstet. 2009;104:85-89.

28. Women Dignity Project and Engendered Health. Risk and resilience: obstetric fistula in Tanzania. An overview of findings and recommendations from the study. Dar es Salaam, Tanzania. 2006. Available from: http://www.engenderhealth.org/files/pubs/maternal-health/risk-andresilience-obstetric-fistula-in-tanzania.pdf. Accessed August 31, 2014.

29. Tafesse B, Muleta M, Michael A, Aytenfesu H. Obstetric fistula and its physical, social and psychological dimension: the Ethiopian scenario. Acta Urol. 2006;23:25-31.

30. Khisa AM, Nyamongo IK. Still living with fistula: an exploratory study of the experience of women with obstetric fistula following corrective surgery in West Pokot, Kenya. Reprod Health Matters. 2012;20:59-66.

31. Plummer K. Labeling theory. Volume 1. Historical, conceptual, and theoretical issues. Colchester, UK: University of Essex. Available from: http://www.sjsu.edu/people/james.lee/courses/soci152/s1/ ajreading10labeling.pdf. Accessed August 31, 2014.

32. Muleta M. Obstetric fistula in developing countries: a review article. J Obstet Gynaecol Can. 2006;28:962-966.

33. Morse JM, Carter B. The essence of enduring and expressions of suffering: the reformulation of self. Sch Inq Nurs Pract. 1996;10: 43-60.

34. Morse JM, Bottorff JL, Hutchinson S. The phenomenology of comfort. J Adv Nurs. 1994;20:189-195. 
International Journal of Women's Health

Dovepress

\section{Publish your work in this journal}

The International Journal of Women's Health is an international, peerreviewed open-access journal publishing original research, reports, editorials, reviews and commentaries on all aspects of women's healthcare including gynecology, obstetrics, and breast cancer. The manuscript management system is completely online and includes Visit http://www.dovepress.com/testimonials.php to read real quotes from published authors.

Submit your manuscript here: http://www.dovepress.com/international-journal-of-womens-health-journal 